\title{
Occupational Stress And Turnover Issues In Public Accounting: The Mediating Effects Of Locus Of Control, Social Support, And Employment Expectations
}

David P. Donnelly, (Email: dvdon@ksu.edu), Kansas State University Jeffrey J. Quirin, (Email: jeffrey.quirin@wichita.edu), Wichita State University

\begin{abstract}
At the aggregate level, turnover costs firms in the accounting profession billions of dollars each year (Larkin 1995). Though the costs of turnover vary widely from firm to firm, one study estimates that each separation costs firms $\$ 4,000$ to $\$ 8,000$ in training and recruiting costs (Roth and Roth 1995). Further complicating the profession's turnover dilemma, changing organizational structures and workforce demographics are forcing public accounting firms to update employee recruitment and retention programs. The increased importance of recruitment and retention efforts coupled with the detrimental effects of turnover have led researchers to gain a better understanding of the voluntary turnover process in public accounting. The demanding and timepressure nature of the public accounting work environment coupled with the profession's lack of success in retaining women and minorities suggests that occupational stress may have an increasingly negative impact on the accounting profession. Through the development and testing of a behavioral-based theoretical model, this study attempts to expand our understanding of the turnover process that transpires in public accounting. The study proposes that three factors act as mediators of occupational stress and subsequently impact employee turnover. Specifically, locus of control (personality type), the perception of adequate social support (a source of additional information), and the bestowing of realistic employment expectations (knowledge acquired at hiring) are all modeled as buffers of occupational stress. Results of a path analytic procedure support the theoretical model suggesting that the aforementioned constructs could become critical components of the accounting profession's recruitment and retention processes.
\end{abstract}

\section{Introduction}

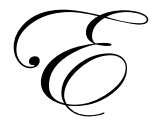

mployee turnover has long been recognized for its negative impact on the accounting profession. Firmspecific effects of employee turnover include decreased client goodwill (Berton 1994; Waller 1985) and lower audit quality resulting from the loss of trained personnel (Hill et al. 1994). Turnover rates for staff and senior auditors are typically 25 percent per year (Roth and Roth 1995). At the aggregate level, turnover costs firms in the accounting profession billions of dollars each year (Larkin 1995). Though the costs of turnover vary widely from firm to firm, one study estimates that each separation costs firms $\$ 4,000$ to $\$ 8,000$ in training and recruiting costs (Roth and Roth 1995). Ernst and Young considers turnover to be far more costly with the costs of hiring and replacing an employee being 150 percent of an employee's annual salary (Cole 1999).

Further complicating the traditional voluntary turnover dilemma facing the profession, organizational structures and the skills necessary to be successful in public accounting are now changing at a very rapid pace. Firms are

Readers with comments or questions are encouraged to contact the authors via email. 
struggling to attract and retain the best candidates with long-term potential to succeed in more demanding roles (Reckers 1995). Additionally, the demographics of the American workforce are also undergoing rapid change (Mynatt et al. 1997). With a large portion of new entrants into the workforce being either immigrants or possessing nonCaucasian ethnicity, it is becoming increasingly important to develop recruitment and retention programs tailored to fit the needs of employees other than the stereotypical, Caucasian male.

The increased importance of recruitment and retention efforts coupled with the detrimental effects of turnover have led researchers to gain a better understanding of the voluntary turnover process in public accounting. The accounting literature has identified numerous factors related to employee turnover including, job satisfaction (Gregson 1992; Bullen and Flamholtz 1987), organizational commitment (Gregson 1992; Aranya et al. 1982), gender (Dalton et al. 1997; Collins 1993), and ethnicity (Mynatt et al. 1997).

One factor in particular, occupational stress, has been linked to turnover in a wide variety of environments including public accounting (Cluskey and Vaux 1997; Rahim 1997, Rahim and Psenicka 1996; Rasch and Harrell 1990; Senatra 1980). Occupational stress, defined as work attributes that pose threats or risks to an employee, results from a poor person-environment fit (Rahim and Psenicka 1996). The demanding and time-pressure nature of the public accounting work environment coupled with the profession's lack of success in retaining women and minorities suggests that occupational stress may have an increasingly negative impact on the accounting profession.

Occupational stress has become a prominent feature of modern organizations with researching suggesting that the antecedents to stress are situation-specific (Rahim and Psenicka 1996; Srivastava and Krishna 1992). Organizational psychologists have begun to identify factors that function as stress buffers (Rahim and Psenicka 1996; Rebele and Michaels 1990). Specifically, stress researchers have begun to examine the buffering effect of various psychological and environmental variables in hopes that the negative outcomes associated with occupational stress can be controlled or eliminated.

The current study attempts to address the accounting profession's turnover and recruitment and retention concerns through the development of a theoretical occupational stress/turnover model. This study posits that in an occupation such as public accounting females and minorities possess greater levels of occupational stress than their male and Caucasian counterparts. Thus, gender and ethnicity are deemed important antecedents of occupational stress in a public accounting setting. Additionally, this study proposes that three additional factors act as mediators of stress. Specifically, an individual's locus of control (personality type), the perceived existence of social support groups (a source of additional information), and the nature of the employment expectations established during the recruitment process (knowledge acquired at hiring) are all viewed as stress-buffers. Finally, the study proposes that increased turnover intentions are a consequence of elevated occupational stress.

Using a cross-organizational design and a path analytic procedure, survey results from 96 public accountants generally support the theoretical model. Results indicate that locus of control, social support, and employment expectations are all significant buffers of occupational stress. Additionally, occupational stress, social support, and employment expectations are significantly associated with turnover intentions. Taken collectively, the results suggest that the mediating variables identified in this study could become critical components of the accounting profession's recruitment, retention, and career development processes.

The remainder of the paper is organized into four sections. The first section overviews the theoretical development including a formulation of the stated hypotheses. A description of the research methodology is contained in the second section, while the empirical results are presented in the third section. The paper then concludes with a discussion of the implications. 


\section{Theoretical Development}

The full theoretical model appears in Figure 1. Each link in the model is labeled with its respective hypothesis and is discussed subsequently. The first links to be discussed involve the antecedent variables followed by a discussion of the mediating variables. The theoretical development portion of the study concludes with a discussion of the consequence variable.

\section{Figure 1 Theoretical Model}

Antecedent
Variables

Mediating

Variables

Dependent

Variable

Consequence

Variable
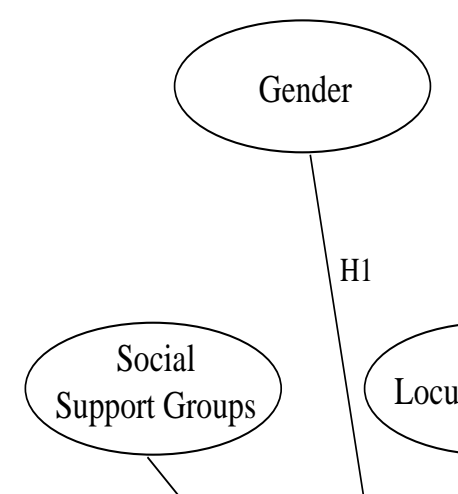

H1

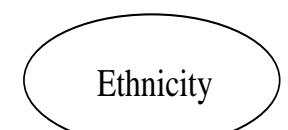

2
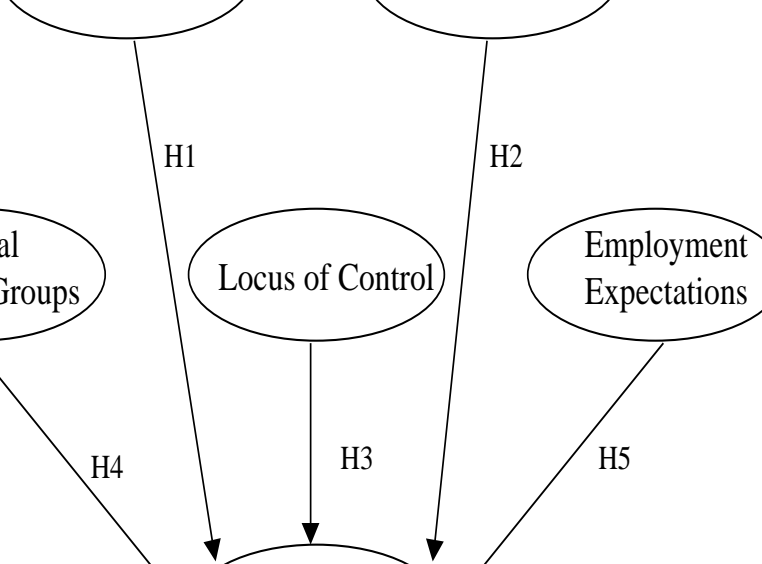

Occupational
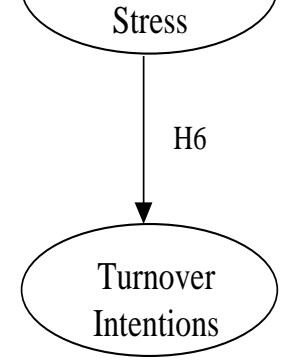

Antecedent variables

A central question being faced by the accounting profession is how to attract qualified individuals with long-term potential, while at the same time increasing minority and female representation (Mynatt et al. 1997). While attracting minority and female members may be challenging enough, retaining them may be even more difficult. Females and minorities are likely to possess characteristics that differ from the Caucasian male. They respond differently to identical situations resulting in different levels of stress among these members. Considerable research has examined gender issues related to women working in male-dominated environments. The findings of this re- 
search have particular relevance to the accounting setting since women are entering, in increasing numbers, public accounting positions traditionally held by men. Results from role conflict theory suggest that female employees possess greater occupational stress levels than males because they typically have greater responsibility for family and household tasks while gainfully employed (Berger et al. 1994). The following hypothesis results:

H1: Female gender is positively associated with occupational stress.

Based on the notion that members of different cultures perceive some stressors differently and exhibit different relationships between stressors and work attitudes (Perrewe et al. 1995), employees of minority ethnicity are also expected to exhibit increased levels of occupational stress. In an occupational stress study designed to capture effects associated with culture, Peterson et al. (1995) found that the level of job-related stress among middle managers from 21 nations varied more by country than by personal or organizational characteristics. Further research indicates that because African-Americans are more likely than Caucasians to belong to lower socioeconomic classes, they are consequently more likely to encounter additional non-employment-related stress factors, thereby increasing their vulnerability to occupational stress (Stroman and Seltzer 1991). This leads to the following hypothesis:

H2: Non-Caucasian ethnicity is positively associated with occupational stress.

\section{Mediating variables}

A personality variable, locus of control, has been used extensively in behavioral research to explain human behavior in organizational settings. Locus of control refers to people's beliefs about the extent to which they control the events that influence their lives (Rotter 1966). Individuals that tend to associate outcomes with their own efforts or believe that events are under their own control are referred to as internals, while externals are those who believe that they cannot control events or outcomes (Spector 1982). Because an individual's perception of stress is a function of the individual's characteristics and the potential source of the stress, there has been considerable research documenting the relationship between locus of control and occupational stress (Cohen and Edwards 1989). Several studies have provided support for the notion that locus of control personality characteristics moderate the adverse effects of occupational stress (Rahim and Psenicka 1996; Cummins 1988). Specifically, internal locus of control has been associated with lower levels of perceived stress (Bernardi 1998; Kobasa et al. 1982), while external locus of control is positively correlated with perceived stress (Jennings 1990). The following hypothesis results:

H3: External locus of control is positively associated with occupational stress.

The existence of adequate social support has been found to reduce stress (Rahim 1997; Rahim and Psenicka 1996; Daniels and Guppy 1994). Social support can be broadly defined as the availability of help from supervisors, co-workers, family members, and friends in times of need. Specifically, social support is considered to be a flow of communication between people involving emotional concern, caring, information, as well as instrumental help (Williams and House 1985). Social support groups help individuals define the real potential harm associated with a particular situation and help to enhance their belief that they can cope with the situation by increasing their perception that others will provide needed resources (Cohen and Wills 1985). Thus, individuals perceiving that adequate social support exists are expected to experience less occupational stress. This leads to the following hypothesis:

H4: Social support is negatively associated with occupational stress.

Employee expectations concerning the job and individual efficacy are also significantly related to the overall level of stress (Maslach and Jackson 1984; Cherniss 1980). Employment expectations are traditionally developed during the recruitment process (Wanous 1973). When expectations are too high, an employee will oftentimes deem them unachievable. The resulting effect is an increased level of occupational stress. The greater the discrepancy the greater the harmful effects on the job. Ward et al. (1986) found that women often enter a male-dominated profession with high expectations concerning promotion and pay but these expectations gradually eroded when faced with the realities of the environment. Additional literature indicates that older, more experienced employees tend to experience lower levels of burnout. Cordes and Dougherty (1993) attribute this phenomenon to an expecta- 
tion shift. That is, more experienced employees shift their expectations to fit the reality of their environment. This stream of literature suggests that unrealistic employment expectations result in inflated levels of occupational stress, and that the recruitment process is a critical point at which realistic expectations can be conferred to the employee. For members of the accounting profession, the bestowing of realistic employment expectations may be a significant factor related to lower levels of perceived occupational stress. The following hypothesis results:

H5: Realistic employment expectations are negatively associated with occupational stress.

\section{Consequence variable}

A substantial body of literature has identified occupational stress as a leading cause of an employee's propensity to leave the organization (Cluskey and Vaux 1997; Rahim 1997; Rahim and Psenicka 1996; Rasch and Harrell 1990; Senatra 1980). This body of literature suggests that occupational stress is an individual's reaction to work environment characteristics that appear threatening to him/her. It indicates a poor fit between the individual abilities and the work environment in which either excessive demands are made from the individual, or the individual is not fully equipped to handle a particular situation (French 1963). Thus, high levels of occupational stress are said to be indications of a poor person-environment fit, which oftentimes lead to turnover. In the current study, turnover intentions are viewed as a function or consequence of occupational stress. That is, employees experiencing higher levels of job-related stress are expected to exhibit a higher intent to turnover. The following hypothesis results:

H6: Occupational stress is positively associated with turnover intentions.

\section{Research Methodology}

Survey procedures

Data was collected by the investigators via a survey questionnaire sent out to a total of 285 public accountants from a cross section of six offices of four public accounting firms. A survey instrument package was distributed to each potential respondent via an office partner and returned by the respondents directly to the researchers via mail to ensure confidentiality. Partners were instructed by the researchers to distribute the survey instruments in a random order throughout their offices. Accompanying each questionnaire was a cover letter containing an explanation of the research as well as instructions for completing the survey. A self-addressed, stamped envelope was also included.

Of the 285 surveys distributed, respondents returned a total of 96 usable surveys for an effective response rate of 34\%. The average respondent was 31 years old and had 5 years of accounting experience. Females represented 58 percent of the returned instruments, while minorities represented 22 percent.

A copy of the research instrument is contained in the Appendix, and descriptive statistics for all measures are reported in Table 1. In addition to gender and ethnicity demographic-related questions, the variables measured in the questionnaire included locus of control, social support, perceived employment expectations, perceived occupational stress, and turnover intentions. Measures of social support, locus of control, and occupational stress were all taken from prior literature, while the employment expectations and turnover intentions instruments were developed. 
Table 1

Descriptive Statistics

\begin{tabular}{l|c|c|c|c}
\hline \hline Variable & Mean & Std. Deviation & Observed Range & Cronbach Alpha \\
\hline Gender $^{\mathrm{a}}$ & 0.58 & 0.49 & $0-1$ & ---- \\
\hline Ethnicity $^{\mathrm{b}}$ & 0.22 & 0.42 & $0-1$ & ---- \\
\hline Locus of Control & 36.69 & 7.23 & $20-67$ & 0.82 \\
\hline Social Support & 47.29 & 5.13 & $35-60$ & 0.72 \\
\hline Employment Expectations & 76.59 & 10.14 & $44-100$ & 0.85 \\
\hline Occupational Stress & 37.80 & 7.95 & $22-66$ & 0.87 \\
\hline Turnover Intentions & 9.17 & 3.62 & $3-15$ & 0.91 \\
\hline \hline
\end{tabular}

${ }^{\mathrm{a}}$ Of the 96 usable survey instruments returned, 56 were identified as coming from females and 40 from males.

${ }^{\mathrm{b}}$ Of the 96 usable survey instruments returned, 21 were identified as coming from minorities and 75 from Caucasians.

\section{Measures}

Locus of control was measured using the 16-item Spector (1988) work locus of control scale. The Rotter (1966) measure was not used due to its extremely general scope. Its items cut across several different domains (e.g., education, work, politics, life in general). The Spector (1988) measure has been shown to possess a stronger fit to work-related outcomes (Blau 1993). Using such concepts as job satisfaction, organizational commitment, role stress, and leadership behavior, Spector (1988) found the work locus of control measure to be significantly related to these work outcomes. Respondents were asked to identify the relationships between reward/outcomes and causes using a five-point Likert-type scale. Higher scores on the work locus of control scale indicate a greater degree of external personality, while lower scores are associated with internal traits. The instrument's reliability and validity have been deemed acceptable in prior research (e.g., Blau 1993; Spector 1988). In the current study, the Cronbach alpha was 0.82 .

A total social support score was constructed by summing three dimensions of emotional social support provided by supervisors; co-workers; and spouse, friends, and relatives. These social support dimensions were measured with the Social Support Scale designed by Caplan et al. (1975). The instrument was cast on a five-point Likerttype scale anchored by (1) not at all and (5) very much. A higher score indicates greater social support received by an employee. A number of studies have reported satisfactory internal consistency reliability of the scale (Rahim 1997). In the current study, the Cronbach alpha was 0.72 .

In order to assess the nature of employees' employment expectations, respondents were asked to compare numerous job experiences with their job expectations prior to joining the organization. A 25 -item employment expectations instrument was developed to evaluate respondents met expectations on both job content and job context dimensions. The instrument was constructed using a five-point Likert format and was based on the earlier works of Lee and Mowday (1987), Jackson et al. (1986), Motowidlo and Lawton (1984), Youngblood et al. (1983), and the Dunnette et al. (1967) job dimension model. An assessment of the instrument's reliability yielded a Cronbach alpha of 0.85 .

Occupational stress was measured using the 15 -item Job Related Tension Index developed by Kahn et al. (1964). The instrument was designed to examine the nature, causes, and consequences of organizational stress in terms of role conflict and role ambiguity. Respondents indicate how frequently they feel bothered about certain features of work. The instrument was written in a five-point Likert-type format anchored by (1) never and (5) nearly all the time. Higher scores indicate a higher degree of occupational stress. A national study of 725 paid employees and self-employed people at all organizational levels indicated satisfactory reliability with a Cronbach coefficient of 0.87 (Christie and Schultz 1998). The Cronbach alpha in the current study was also 0.87.

Accounting studies have used somewhat different measures of employee turnover intentions (Scandura and Viator 1994; Aranya et al. 1982; Senatra 1980; Dillard and Ferris 1979; and others). Given the promotion/tenure characteristics of the public accounting profession, the current study was interested in not only capturing the respon- 
dent's immediate turnover intentions but also his/her long-term intent. This multi-time period approach is supported by prior literature (Scandura and Viator 1994; Aranya and Ferris 1984).

A three-item turnover intentions scale was developed to capture the respondents' immediate turnover intentions (within 2 years), middle-term turnover intentions (within 5 years), and long-term intentions (until retirement). The items were written in a five-point Likert-type format anchored by (1) strongly disagree and (5) strongly agree. Items were then reverse-scored so that higher values indicate a higher degree of turnover intent. An analysis was undertaken to ascertain the instrument's reliability. The resulting Cronbach alpha was 0.91 .

\section{Path analysis}

Path analysis was used to evaluate the proposed hypotheses. Path analysis, rather than moderated regression analysis (MRA) or ANOVA, was used because the theoretical model presented in the study is viewed as an antecedent and consequence nomological framework for occupational stress. Use of path analysis for testing of such frameworks as well as contingency-based hypotheses, like those contained in this study, has been suggested as the statistical method of choice in recent literature (Hartmann and Moers 1999; Shields and Shields 1998).

The path model used in the analysis corresponds to the model in Figure 1. In Figure 1, each link between the variables has a path coefficient that measures the impact of the antecedent variable in explaining the variance in the outcome variable. For example, the path coefficient for the link between locus of control and occupational stress indicates the increase in occupational stress, measured in standard deviations, associated with a one standard deviation increase in locus of control. Values for the path coefficients were estimated using regression and correlation analysis (Asher 1983). The path coefficient value is the standardized beta coefficient found by regressing the outcome variable on the appropriate antecedent variable(s).

\section{Empirical Results}

\section{Main analysis}

Table 2 reports the correlation matrix for the variables. Table 3 presents the results of the main analysis and lists each hypothesis and its corresponding path coefficient, each of which were estimated using regression or correlation analysis.

Table 2

Correlation Matrix

\begin{tabular}{|c|c|c|c|c|c|c|c|}
\hline & $\begin{array}{l}\text { Gender } \\
\text { (1) }\end{array}$ & $\begin{array}{l}\text { Ethnicity } \\
\text { (2) }\end{array}$ & $\begin{array}{l}\text { Locus } \\
\text { of Control } \\
(3)\end{array}$ & $\begin{array}{l}\text { Social } \\
\text { Support } \\
(4)\end{array}$ & $\begin{array}{l}\text { Employment } \\
\text { Expectations (5) }\end{array}$ & $\begin{array}{l}\text { Occupational } \\
\text { Stress } \\
(6)\end{array}$ & $\begin{array}{l}\text { Turnover } \\
\text { Intentions } \\
(7)\end{array}$ \\
\hline (1) & 1.000 & & & & & & \\
\hline (2) & $0.192 * *$ & 1.000 & & & & & \\
\hline (3) & 0.001 & 0.097 & 1.000 & & & & \\
\hline (4) & $0.139^{*}$ & -0.015 & $-0.397 * * *$ & 1.000 & & & \\
\hline (5) & 0.014 & -0.124 & $-0.452 * * *$ & $0.424 * * *$ & 1.000 & & \\
\hline (6) & -0.002 & 0.087 & $0.519 * * *$ & $-0.538 * * *$ & $-0.500 * * *$ & 1.000 & \\
\hline (7) & 0.068 & $0.136^{*}$ & $0.363 * * *$ & $-0.181 * *$ & $-0.382 * * *$ & $0.359 * * *$ & 1.000 \\
\hline $\begin{array}{l}\mathrm{n}=96 \\
\text { One t } \\
* \mathrm{p}<1 \\
* * \mathrm{p}<. \\
* * * \mathrm{p}\end{array}$ & signific & & & & & & \\
\hline
\end{tabular}


Table 3

Path Analysis Results

\begin{tabular}{|c|c|c|c|c|c|}
\hline $\begin{array}{c}\text { Dependent } \\
\text { Variable }\end{array}$ & $\begin{array}{c}\text { Independent } \\
\text { Variable } \\
\end{array}$ & $\begin{array}{l}\text { Associated } \\
\text { Hypothesis }\end{array}$ & $\begin{array}{c}\text { Path } \\
\text { Coefficient }\end{array}$ & t-statistic & p-value \\
\hline \multirow[t]{5}{*}{ OS } & GN & $\mathrm{H} 1$ & 0.044 & 0.54 & 0.295 \\
\hline & ET & $\mathrm{H} 2$ & 0.017 & 0.22 & 0.415 \\
\hline & $\mathrm{LC}$ & $\mathrm{H} 3$ & 0.281 & 3.07 & 0.001 \\
\hline & SS & $\mathrm{H} 4$ & -0.335 & -3.69 & 0.001 \\
\hline & $\mathrm{EE}$ & $\mathrm{H} 5$ & -0.230 & -2.47 & 0.008 \\
\hline \multirow[t]{4}{*}{ TI } & OS & H6 & 0.191 & 1.54 & 0.063 \\
\hline & $\mathrm{LC}$ & $\begin{array}{ll}---- \\
-1\end{array}$ & 0.194 & 1.71 & 0.045 \\
\hline & $\mathrm{SS}$ & ----- & 0.101 & 0.89 & 0.188 \\
\hline & $\mathrm{EE}$ & $\begin{array}{ll}---- \\
\end{array}$ & -0.241 & -2.13 & 0.018 \\
\hline
\end{tabular}

Hypothesis 1 predicts that there is a positive relation between female gender and occupational stress. The path coefficient linking gender and occupational stress is 0.044 and is insignificant. Thus, on the basis of path analysis females appear to experience similar levels of occupational stress than males. A supplemental mean t-test supports this contention as female and male mean levels of occupational stress were indifferent at 37.79 and 37.83 , respectively.

Hypothesis 2 predicts that there is a positive association between Non-Caucasian ethnicity and occupational stress. The corresponding path coefficient is 0.017 and is insignificant. Thus, employees possessing minority and Caucasian backgrounds experience similar levels of occupational stress. Supplemental mean analysis once again supports this claim with minority and Caucasian stress levels being statistically indifferent at 39.10 and 37.44 , respectively.

Hypothesis 3 states that there is a positive relationship between external locus of control and occupational stress. The path coefficient linking these two variables is 0.281 and is significant at the p<.001 level. This result provides support for hypothesis 3 and suggests that external (internal) employees perceive more (less) occupational stress.

Hypothesis 4 predicts that there is a negative relationship between social support and occupational stress. The path coefficient linking these two variables is -0.335 and is significant at the $p<.001$ level. This result supports hypothesis 4 and suggests that employees possessing higher amounts of social support experience lower levels of occupational stress.

Hypothesis 5 predicts that there is a negative relationship between realistic employment expectations and occupational stress. The path coefficient for this theoretical link is -0.230 and is significant at the p<.008 level. Thus, employees who view that realistic employment expectations were communicated to them at the time of hire subsequently experience lower levels of occupational stress.

Hypothesis 6 predicts that there is a positive relationship between occupational stress and turnover intentions. The path coefficient for this theoretical link is 0.191 and is significant at the $\mathrm{p}<.063$ level. Thus, employees who exhibit higher levels of occupational stress are more likely to leave their employing firms.

\section{Additional analysis: Employment expectations main effects}

A somewhat interesting result is depicted in the turnover intentions portion of Table 3 . With a path coefficient of -0.241 , the realistic employment expectations variable is a highly-significant predictor of an employee's in- 
tent to turnover. This finding suggests that a significant portion of an employee's turnover decision may be attributed to his/her perception of the employment expectations set forth by the employing organization. Table 4 reports the results of an additional employment expectations mean analysis that was undertaken. For the purpose of this analysis, the sample was split at the median employment expectations value. Those scoring above the median perceive a high degree of realism in the employment expectations, while those scoring below the median view the employment expectations somewhat less realistic. Results reveal that those perceiving a higher degree of realism in employment expectations possess significantly lower levels of occupational stress and turnover intentions. Thus, providing a realistic view of employment to prospective employees appears to result in lower stress and lower turnover.

Table 4

Employment Expectations Mean Analysis

\begin{tabular}{|c|c|c|c|}
\hline & $\begin{array}{c}\text { Low Expectations } \mathrm{n}=48 \\
\text { Mean } \\
\text { (Std. Dev.) }\end{array}$ & $\begin{array}{c}\text { High Expectations } n=48 \\
\text { Mean } \\
\text { (Std. Dev.) }\end{array}$ & $\begin{array}{l}\text { t statistic } \\
\text { (p value) }\end{array}$ \\
\hline Occupational Stress & $\begin{array}{r}40.10 \\
(8.92) \\
\end{array}$ & $\begin{array}{r}35.50 \\
(6.10) \\
\end{array}$ & $\begin{array}{c}2.95 \\
(.002) \\
\end{array}$ \\
\hline Turnover Intentions & $\begin{array}{l}10.25 \\
(3.64)\end{array}$ & $\begin{array}{c}8.08 \\
(3.30)\end{array}$ & $\begin{array}{l}3.05 \\
(.001)\end{array}$ \\
\hline
\end{tabular}

\section{Additional analysis: Locus of control main effects}

The high correlation between the locus of control construct and a large number of the other variables of interest (as shown in Table 2) prompted an additional main effect mean analysis to ascertain the overall impact of the locus of control variable. For this purpose, the sample was split at the median locus of control value. Those scoring above (below) the median were classified as externals (internals). This resulted in 48 internals and 48 externals. Table 5 reports that externals reported a lower amount of social support $(\mathrm{p}<.001)$, reported lower realistic employment expectations $(\mathrm{p}<.001)$, possessed higher levels of occupational stress $(\mathrm{p}<.001)$, and had higher turnover intentions $(\mathrm{p}<.001)$ than internals. These results suggest that locus of control may play an important role in reducing occupational stress and managing turnover.

Table 5

Locus of Control Mean Analysis

\begin{tabular}{l|ccc}
\hline \hline & $\begin{array}{c}\text { Internals n= 48 } \\
\text { Mean } \\
\text { (Std. Dev.) }\end{array}$ & $\begin{array}{c}\text { Externals n = 48 } \\
\text { Mean } \\
\text { (Std. Dev.) }\end{array}$ & $\begin{array}{c}\text { t statistic } \\
\text { (p value) }\end{array}$ \\
\hline Social Support & 49.60 & 44.98 & 4.93 \\
& $(4.80)$ & $(4.38)$ & $(.001)$ \\
\hline Employment Expectations & 79.81 & 73.38 & 3.26 \\
& $(8.30)$ & $40.95)$ & $(.001)$ \\
\hline Occupational Stress & 34.63 & $(8.17)$ & -4.25 \\
& $(6.35)$ & 10.48 & $(.001)$ \\
\hline Turnover Intentions & 7.85 & $(3.38)$ & -3.79 \\
& $(3.40)$ & & $(.001)$ \\
\hline \hline
\end{tabular}

\section{Additional analysis: Further breakdown of social support}

The overall, significant effect of social support on occupational stress led the researchers to analyze this relationship in more detail. The main analysis utilized a total social support score which was constructed by summing 
three dimensions of emotional social support provided by (1) supervisors; (2) co-workers; and (3) spouse, friends, and relatives. The researchers determined that a further breakdown of the social support instrument into the three categories might be useful from an application standpoint. That is, if one of the three categories of social support were to have a high degree of correlation with occupational stress relative to the other categories, then organizations might be best served to focus initial social support improvement efforts on this one dimension. An additional correlation analysis was therefore undertaken to further ascertain the relative relationships among occupational stress and the individual social support constructs. The results of this analysis, which are presented in Table 6 , reveal that all three dimensions of social support are significantly correlated with occupational stress. With a correlation coefficient of -0.516, an individual's perceived existence of social support from co-workers has the highest degree of correlation with his/her reported stress level. This suggests that while social support from an employee's supervisor and spouse, friends, and relatives may indeed be important mediators of occupational stress, the possession of a stable co-worker social support network is the most important means of reducing and/or controlling occupational stress.

Table 6

Correlation Matrix of Occupational Stress and Social Support Dimensions

\begin{tabular}{|c|c|c|c|c|}
\hline & $\begin{array}{c}\text { Occupational Stress } \\
\text { (1) }\end{array}$ & $\begin{array}{l}\text { Social Support from } \\
\text { Supervisor }(2)\end{array}$ & $\begin{array}{l}\text { Social Support from } \\
\text { Co-workers (3) }\end{array}$ & $\begin{array}{c}\text { Social Support from } \\
\text { Spouse, Friends, \& Rela- } \\
\text { tives (4) }\end{array}$ \\
\hline (1) & 1.000 & & & \\
\hline (2) & $-0.391 * * *$ & 1.000 & & \\
\hline (3) & $-0.516 * * *$ & $0.341 * * *$ & 1.000 & \\
\hline (4) & $-0.156 * *$ & 0.003 & 0.062 & 1.000 \\
\hline
\end{tabular}

\section{Conclusions and Implications}

Attracting and retaining qualified employees is a substantial element of the accounting profession's human resource function. For many years, employee retention has been the subject of extensive examination in the industrial psychology area. A certain factor, occupational stress, has been linked to employee turnover in a variety of environments. Results of the current study suggest that an individual's personality type (locus of control), the perceived existence of social support groups, and the nature of the employment expectations established during the recruitment process can be important buffers of occupational stress. Contrary to expectations, however, the study finds that females and males as well as minorities and Caucasians possess similar levels of occupational stress.

The mediating factors identified in this study look promising as components of the accounting profession's recruitment, retention, and career development processes. First, the locus of control variable appears to possess a significant ability to explain the existence of social support, the perceived realism of employment expectations, the reported level of occupational stress, as well as the exhibited turnover intentions. Because locus of control literature suggests that internals and externals react quite differently to similar circumstances and/or stimuli, it may be useful for supervisors to understand the personality types of their subordinates. Knowledge of this trait should enable supervisors to provide a better employee/job assignment match and be more effective during their interaction with subordinates. Second, the concept of co-worker social support groups could be introduced by the profession during the recruitment process. Preconceived notions regarding the level of stress experienced during employment within the profession could be countered by recruiters with discussions of the positive, buffering roles that support groups have been able to provide members. It is expected that the results of this study could help accounting firms identify a variety of formal and informal support networks that will decrease the level of occupational stress for employees and thus improve their retention and subsequently increase the overall diversity, experience, and quality of the pub- 
lic accounting workforce. Third, the bestowing of realistic employment expectations appears to have a significant impact on occupational stress and intent to turnover. Employers offering a realistic job preview will likely witness employees achieving a better initial organizational fit based on accurate expectations.

An additional implication of this study relates to the employee shock literature. Empirical evidence suggests that females and minorities are, in general, more prone to employment-related shocks (Lee and Mitchell 1994). If firm experience reveals that women and/or those of non-traditional ethnicity experience increased levels of difficulty when encountering certain assignments or specific aspects of the organization, these issues could be addressed during the recruitment and/or orientation phase of the employment process. Additional discussion could occur on an ongoing basis through the social support networks. The revelation of such information allows for an employee expectation shift to occur thereby reducing the level of occupational stress.

When assessing the implications of this study it is necessary to note that the findings are subject to a number of limitations. First, survey studies are subject to both lack of control limitations and potential bias associated with self-reporting. Second, problems of omitted and uncontrolled intervening or moderating variables may exist. Lastly, path analysis relies on correlation, which does not prove causality. Theory driven linkages in conjunction with empirical support suggests causal linkages as specified in Figure 1. Alternative methodologies, such as controlled experiments, could provide stronger evidence of causality.

This study was sponsored by a grant from the Department of the Navy, Office of Naval Research, through The University of Mississippi. Its contents do not necessarily reflect the position or the policy of the Government or The University of Mississippi, and no official endorsement should be inferred.

\section{Bibliography}

1. Aranya, N., and K. R. Ferris. 1984. A reexamination of accountants organizational-professional conflict. The Accounting Review (January): 1-15.

2. L R. Lachman, and J. Amernic. 1982. Accountants' job satisfaction: A path analysis. Accounting, Organizations and Society 7: 201-215.

3. $\quad$ Asher, R. 1983. Causal modeling. London: Sage.

4. Berger, P., A. Cook, R. DelCampo, R. Herrera, and R. Weigel. 1994. Family/work roles' relation to perceived stress: Do gender and ethnicity matter? Journal of Family and Economic Issues 15: 223-242.

5. Bernardi, R. 1998. The relationships among locus of control, perception of stress, and performance. Journal of Applied Business Research 13: 1-8.

6. Berton, L. 1994. Booked up: Big accounting firms striving to cut costs, irritate small clients; many companies say service has slipped badly, hurt in part by staff turnover. Wall Street Journal (April 21): A1 (E), A8.

7. Blau, G. 1993. Testing the relationship of locus of control to different performance dimensions. Journal of Occupational and Organizational Psychology 66: 125-138.

8. Bullen, M. L., and E. G. Flamholtz. 1987. A theoretical and empirical investigation of job satisfaction and intended turnover in the large CPA firm. Accounting, Organizations and Society 10: 287-302.

9. Caplan, R., S. Cobb, J. French, R. Harrison, and S. Pinneau. 1975. Job demands and worker health. Washington, DC: Department of Health, Education, and Welfare.

10. Cherniss, C. 1980. Staff burnout: Job stress in the human services. Beverly Hills, CA: Sage.

11. Christie, M., and K. Schultz. 1998. Gender differences on coping with job stress and organizational outcomes. Work \& Stress 12: 351-361.

12. Cluskey, G., and A. Vaux. 1997. Vocational misfit: Source of occupational stress among accountants. Journal of Applied Business Research 13: 43-54.

13. Cohen, S., and J. Edwards. 1989. Personality characteristics as moderators of the relationship between stress and disorders. In Advances in the investigation of psychological stress. New York, NY: Wiley.

14. Cohen, S., and T. Wills. 1985. Stress, social support, and the buffering hypothesis. Psychological Bulletin 109: 5-24.

15. Cole, J. 1999. E\&Y creates office of retention and turnover rates drop. HR Focus 76: 7-8. 
16. Collins, K. M. 1993. Stress and departures from the public accounting profession: A study of gender differences. Accounting Horizons 7: 29-38.

17. Cordes, C., and T. Dougherty. 1993. A review and an integration of research on job burnout. Academy of Management Review 18: 621-656.

18. Cummins, R. 1988. Perceptions of social support, receipt of supportive behaviors, and locus of control as moderators of the effects of chronic stress. American Journal of Community Psychology 16: 685-699.

19. Dalton, D. R., J. W. Hill, and R. J. Ramsay. 1997. Women as managers and partners: Context specific predictors of turnover in international public accounting firms. Auditing: A Journal of Practice \& Theory 16: 29-50.

20. Daniels, K., and A. Guppy. 1994. Occupational stress, social support, job control, and psychological wellbeing. Human Relations 47: 1523-1544.

21. Dillard, J. F., and K. R. Ferris. 1979. Sources of professional staff turnover in public accounting firms: Some further evidence. Accounting Organizations and Society 4: 179-186.

22. Dunnette, M., J. Campbell, and M. Hakel. 1967. Factors contributing to job satisfaction and job dissatisfaction in six occupational groups. Organizational Behavior and Human Performance 2: 143-174.

23. French, J. 1963. The social environment and mental health. Journal of Social Issues 19: 39-56.

24. Gregson, T. 1992. An investigation of the causal ordering of job satisfaction and organizational commitment in turnover models in accounting. Behavioral Research in Accounting 4: 80-95.

25. Hartmann, F., and F. Moers. 1999. Testing contingency hypotheses in budgetary research: An evaluation of the use of moderated regression analysis. Accounting, Organizations and Society 24: 291-315.

26. Hill, J. W., M. B. Metzger, and J. Wermert. 1994. The spectre of disproportionate auditor liability in the s\&l crisis. Critical Perspectives on Accounting 5: 133-177.

27. Jackson, S., R. Schwab, and R. Schuler. 1986. Toward an understanding of the burnout process. Journal of Applied Psychology 4: 630-640.

28. Jennings, B. 1990. Stress, locus of control, social support, and psychological symptoms among head nurses. Research in Nursing and Health December: 393-401.

29. Kahn, R., D. Wolfe, R. Quinn, and R. Snoek. 1964. Organizational stress: Studies in role conflict and ambiguity. New York, NY: Wiley.

30. Larkin, J. 1995. Managing employee turnover is everyone's business. National Public Accountant 40: 3436.

31. Lee, T. W., and T. R. Mitchell. 1994. An alternative approach: the unfolding model of voluntary employee turnover. Academy of Management Journal. 19-1: 51-89.

32. Lee, T., and R. Mowday. 1987. Voluntarily leaving an organization: an empirical investigation of Steers and Mowday's model of turnover. Academy of Management Journal 30: 721-743.

33. Kobasa, C., S. Maddi, and S. Kahn. 1982. Hardiness and health: A prospective study. Journal of Personality and Social Psychology 42: 168-177.

34. Maslach, C., and S. Jackson. 1984. Patterns of burnout among a national sample of public contact workers. Journal of Health and Human Resources Administration 7: 189-212.

35. Motowidlo, S., and G. Lawton. 1984. Affective and cognitive factors in soldiers' reenlistment decisions. Journal of Applied Psychology 69: 157-166.

36. Mynatt, P., J. Omundson, R. Schroeder, and M. Stevens. 1997. The impact of anglo and hispanic ethnicity, gender, position, personality, and job satisfaction on turnover intentions: A path analytic investigation. Critical Perspectives on Accounting 8: 657-683.

37. Perrewe, P., D. Ralston, and D. Fernandez. 1995. A model depicting the relations among perceived stressors, role conflict, and organizational commitment: A comparative analysis of Hong Kong and the United States. Asia Pacific Journal of Management 12: 1-20.

38. Peterson, M., P. Smith, A. Akande, and S. Ayestaran. 1995. Role conflict, ambiguity, and overload: A 21 nation study. Academy of Management Journal 38: 429-452.

39. Rahim, M. 1997. Relationships of stress, locus of control, and social support to psychiatric symptoms and propensity to leave a job: A field study with managers. Journal of Business and Psychology 12: 159-174.

40. Rahim, M., and C. Psenicka. 1996. A structural equations model of stress, locus of control, social support, psychiatric symptoms, and propensity to leave a job. The Journal of Social Psychology 136: 69-84. 
41. Rasch, R., and A. Harrell. 1990. The impact of personal characteristics on the turnover behavior of accounting professionals. Auditing: A Journal of Practice \& Theory 9: 90-102.

42. Rebele, J. and R, Michaels. 1990. Independent auditors' role stress: Antecedent, outcome, and moderating variables. Behavioral Research in Accounting 2: 124-153.

43. Reckers, P. 1995. Know thy customer. In Change in accounting education: A research bulletin. Federation of Schools of Accountancy: 29-35.

44. Roth, P. G., and P. L. Roth. 1995. Reduce turnover with realistic job previews. CPA Journal 65: 68-69.

45. Rotter, J. B. 1966. Generalized expectancies for internal versus external control of reinforcement. Psychological Monographs 80 (1) whole no. 609.

46. Scandura, T. A., and R. E. Viator. 1994. Mentoring in public accounting firms: An analysis of mentorprotégé relationships, mentorship functions, and protégé turnover intentions. Accounting, Organizations and Society 19: 717-734.

47. Senatra, P. T. 1980. Role conflict, role ambiguity, and organizational climate in a public accounting firm. The Accounting Review (October): 594-603.

48. Shields, J., and M. Shields. 1998. Antecedents of participative budgeting. Accounting, Organizations and Society 23: 49-76.

49. Spector, P. E. 1982. Behavior in organizations as a function of employee's locus of control. Psychological Bulletin 91: 482-497.

50. $\quad$ 1988. Development of the work locus of control scale. Journal of Occupational Psychology 61: 335-340.

51. Srivastava, A., and A. Krishna. 1992. Moderating effects of locus of control on the relationship between occupational stress and job strain. Journal of Psychological Researches 36: 53-58.

52. Stroman, C., and R. Seltzer. 1991. Racial differences in coping with job stress. Journal of Social Behavior and Personality 6: 309-318.

53. Waller, W. 1985. Self-selection and the probability of quitting: A contracting approach to employee turnover in public accounting. Journal of Accounting Research 23: 817-828.

54. Wanous, J. 1973. Effects of realistic job preview on job acceptance, job attitudes, and job survival. Journal of Applied Psychology 58: 327-332.

55. Ward, S., O. Moseley, and D. Ward. 1986. The woman CPA: A question of job satisfaction. The Woman CPA April: 4-10.

56. Williams, D., and J. House. 1985. Social support and stress reduction. In Job stress and blue collar work. Chichester: Wiley.

57. Youngblood, S., W. Mobley, and B. Meglino. 1983. A longitudinal analysis of the turnover process. Journal of Applied Psychology 68: 507-516. 


\section{Appendix}

Survey Instruments (Items 1, 2, 3, 4, 7, 11, 14, and 15 are reverse scored)

The following statements identify relationships between reward/outcomes and their causes. Please indicate the extent of your agreement with each statement by circling a number from 1 to 5 based on the following scale:

$$
1=\text { Strongly Disagree } \quad 5=\text { Strongly Agree }
$$

1. A job is what you make of it.

2. On most jobs, people can pretty much accomplish whatever they set out to accomplish.

3. If you know what you want out of a job, you can find a job that gives that to you.

4. If employees are unhappy with a decision made by their boss, they should do something about it.

5. Getting the job you want is mostly a matter of luck.

6. Making money is primarily a matter of good fortune.

7. Most people are capable of doing their jobs well if they make an effort.

8. In order to get a really good job, you need to have family members or friends in high places.

9. Promotions are usually a matter of good fortune.

10. When it comes to landing a really good job, who you know is more important than what you know.

11. Promotions are given to employees who perform well on the job.

12. To make a lot of money you have to know the right people.

13. It takes a lot of luck to be an outstanding employee at most jobs.

14. People who perform their jobs well generally get rewarded for it.

15. Most employees have more influence on their supervisors than they think.

16. The main difference between people who make a lot of money and people who make a little money is luck.

\section{Social Support}

The following statements relate to your perceptions of the social support that currently exists in your life. Please indicate your response to each statement by circling a number from 1 to 5 based on the following scale:

\section{$1=$ Don't Have Any Such Person $\quad 5$ = Very Much}

1. How much does each of these people go out of their way to do things to make your work life easier for you?

a. Your immediate supervisor (boss)

b. Other people at work

c. Your spouse, friends, and relatives

2. How easy is it to talk with each of the following people?

a. Your immediate supervisor (boss)

b. Other people at work

c. Your spouse, friends, and relatives

3. How much can each of these people be relied on when things get tough at work?

a. Your immediate supervisor (boss)

b. Other people at work

c. Your spouse, friends, and relatives 
4. How much is each of the following people willing to listen to your personal problems?

a. Your immediate supervisor (boss)

b. Other people at work

c. Your spouse, friends, and relatives

\section{Employment Expectations}

For each of the following statements, you are to compare what you expected prior to joining your current employer with what you have experienced while being employed. Please indicate your response to each statement by circling a number from 1 to 5 based on the following scale:

\section{$1=$ Much Less than Expected}

\section{$5=$ Much More than Expected}

1. The amount of achievement I feel from my job.

2. The amount of variety provided by my job.

3. The amount of decision making power I have in my job.

4. The amount of work I am assigned.

5. The importance of my job.

6. The amount of recognition I receive for doing a good job.

7. The personal interest officers/supervisors have in me.

8. The technical competence of my supervisor.

9. My supervisor's willingness to listen to me.

10. The technical competence of my co-workers.

11. My personal interaction with co-workers.

12. My opportunities for promotion.

13. The availability of job training/educational opportunities.

14. The opportunities available to me to develop new skills.

15. The salary I receive.

16. The insurance/housing/health/other benefits provided.

17. The amount of job security I have.

18. My physical working conditions.

19. Communication of company policies and practices.

20. The amount of time I am away from family/friends.

21. The extent to which my job interferes with my marriage/friendship.

22. The pride I have in what I do.

23. My overall quality of life.

24. The company's acceptance of gender-related differences.

25. The company's acceptance of ethnic/cultural-related differences.

\section{Occupational Stress}

The following statements represent a list of things that oftentimes bother people at work. Please indicate how frequently you feel bothered by each of them during your current employment by circling a number from 1 to 5 based on the following scale:

$$
1=\text { Never }
$$

\section{$5=$ Nearly All of the Time}

1. Feeling that you have too little authority to carry out the responsibilities assigned to you.

2. Being unclear on just what the scope and responsibilities of your job are.

3. Not knowing what opportunities for advancement or promotion exist for you.

4. Feeling that you have too heavy of a workload, one that you can't possibly finish during an ordinary day.

5. Thinking that you'll not be able to satisfy the conflicting demands of various people over you. 
6. Feeling that you're not fully qualified to handle your job.

7. Not knowing what your supervisor thinks of you, how he/she evaluates your performance.

8. The fact that you can't get information needed to carry out your job.

9. Having to decide things that affect the lives of individuals, people that you know.

10. Feeling that you may not be liked and accepted by the people you work with

11. Feeling unable to influence your immediate supervisor's decisions and actions that affect you.

12. Not knowing just what the people you work with expect of you.

13. Thinking that the amount of work you have to do may interfere with how well it gets done.

14. Feeling that you have to do things on the job that are against your better judgment.

15. Feeling that your job tends to interfere with your family life.

\section{Turnover Intentions (All items reverse-scored)}

The following statements relate to your expectations concerning staying employed by your current employer. Please indicate the extent of your agreement with each statement by circling a number from 1 to 5 based on the following scale:

\section{$1=$ Strongly Disagree $\quad 5=$ Strongly Agree}

1. I plan to remain with my current employer until I retire.

2. I plan to remain with my current employer for at least two more years.

3. I plan to remain with my current employer for at least five more years. 